\title{
National dental surveys
}

\section{Whatever \\ improvements are made in the future, let \\ no one forget the phenomenal impact that two committed, professional and caring individuals, Jean Todd and Andy Anderson, had on the development of our} national dental surveys

John Murray Dean of Dentistry, Newcastle Dental School

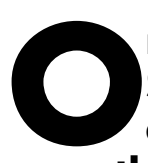

n the 23rd of March the 1998 Adult Dental Health Survey was published. To accompany this important event a series of articles will be published in the BDJ over the next few months discussing specific issues from the survey. We need to reflect on the fact that this is the latest in a series of studies that began $\mathbf{3 0}$ years ago, alternating an Adult Dental Health Survey with a Children's Dental Health Survey every five years. They have all provided a wealth of information, which has been of enormous value in shaping dental services.

But behind the publication of these vital documents is a personal story, which ended in sadness for all those involved in the surveys. Jean Todd and Professor Roger (Andy) Anderson worked together on the first national survey in 1968, and their deaths, in 1996 and 1999 respectively, brought to an end the contributions they both made to dental epidemiology in the United Kingdom.

It is well known that Jean Todd developed a deep understanding of the impact of various factors on dental statistics and became a very valuable part-time member of the Dental Practice Board. She had an almost obsessional desire to ensure that the changes in child and adult dental health were communicated to a wide audience. So great was Jean's commitment to the national dental surveys that she declined promotion within Government Social Survey, preferring to work as a research officer. However increasing ill health meant that, although she was present at the training days for the 1993 Children's Dental Health Survey, she was not involved in writing the report. Jean finally gave up the fight, having endured a painful and debilitating illness, and died in 1996.

Andy Anderson, as a member of the Standing Dental Advisory Committee, gave extremely strong support to the continuation of the national dental surveys. He welcomed innovation and was delighted when, for the 1998 Adult Dental Health Survey, it was decided to input data directly from the clinical examination at the chairside by computer. He had an encyclopaedic knowledge of the use of computers in dentistry. Although he was still associated with the Birmingham team planning the 1998 survey, sadly he died in 1999 before the early results of the survey became available.

The surveys themselves have naturally changed over the years. In the latest survey the diagnosis of caries and periodontal disease has been expanded, an assessment made of adhesive bridges and veneers, and sophisticated sociological measures have been introduced, to ensure a patient-based measure of health, rather than focusing merely on disease. This and other improvements that have been made to the 1998 Survey reflect the changing nature of oral health in the population and enable new benchmarks to be set so that variations in the oral health of the population in the future can be monitored. At the same time the results of the present study can be set in context and compared with previous studies. Thirty years ago 37\% of adults in England and Wales aged 16 years and over were edentulous, now the proportion has fallen to $12 \%$. This kind of information is vital to those planning longterm healthcare, but also to individual practitioners estimating the direction of their practices.

The national surveys of dental health provide an invaluable source of information on the changing pattern of oral health in the United Kingdom. Whatever improvements are made in the future, let no one forget the phenomenal impact that two committed, professional and caring individuals, Jean Todd and Andy Anderson, had on the development of our national dental surveys, for over 25 years. 